\title{
Correction to: Distributionally robust optimization with multiple time scales: valuation of a thermal power plant
}

\author{
Wim van Ackooij ${ }^{1}$ (D) Debora Daniela Escobar ${ }^{2} \cdot$ Martin $_{\text {Glanzer }}^{2}$ (D) \\ Georg Ch. Pflug ${ }^{2,3}$ iD
}

Received: 28 November 2019 / Accepted: 4 December 2019 / Published online: 10 December 2019

(c) The Author(s) 2019

\section{Correction to: Computational Management Science https://doi.org/10.1007/s10287-019-00358-0}

The original version of this article unfortunately contained a mistake in Eq. (1). The correct expression is given below:

$$
\begin{aligned}
\max _{\left\{u_{t}\right\}_{t=0}^{T-1}} \mathbb{E} & {\left[\sum_{t=0}^{T-1} \beta_{t} h_{t}\left(z_{t}, u_{t}, \xi_{t}\right)\right] } \\
\text { s.t. } & z_{t+1}=g_{t}\left(z_{t}, u_{t}, \xi_{t+1}\right) \quad \forall t=0, \ldots, T-1 \\
& u_{t} \in \mathcal{U}_{t}\left(z_{t}\right) \text { a.s. } \forall t=0, \ldots, T-1, u_{t}=u_{t}\left(z_{t}, \xi_{t}\right), \\
z_{t} & \in \mathcal{Z}_{t} \text { a.s. } \forall t=0, \ldots, T-1
\end{aligned}
$$

Publisher's Note Springer Nature remains neutral with regard to jurisdictional claims in published maps and institutional affiliations.

The original article can be found online at https://doi.org/10.1007/s10287-019-00358-0.

Martin Glanzer

martin.glanzer@univie.ac.at

1 OSIRIS, EDF R\&D, 7 Boulevard Gaspard Monge, 91120 Palaiseau, France

2 Department of Statistics and Operations Research, University of Vienna, Oskar-Morgenstern-Platz 1, 1090 Wien, Austria

3 International Institute for Applied Systems Analysis (IIASA), Laxenburg, Austria 